\section{(1)}

CrossMark

\title{
Misinterpretation of time-to-first event curves can lead to inappropriate treatment
}

\author{
To the Editor:
}

Great care should be taken when assessing the consistency of treatment effect over time based on a survival curve plot, and even more so when a treatment affects a repeating event end-point, such as exacerbations, rather than an event that can occur only once, like death.

In their recent editorial in the European Respiratory Journal, SUISSA and ARIEL [1] make the assertation that survival functions plotted from Kaplan-Meier estimates from figure 1b in the IMPACT study [2] "clearly show that the difference in the rate of exacerbation between LAMA/LABA/ICS and LAMA/LABA over follow-up is due to the first month's surge, with practically no differences in the subsequent rates between the two groups". However, this statement is based on a misunderstanding of the survival analyses presented.

The events plotted on the figure are the first moderate or severe COPD exacerbations experienced by a patient in the IMPACT study. The statements made by SuISSA and ARIEL [1] about exacerbation rates refer to the rate of first exacerbations only, and not to the rate of all exacerbations during the study.

Their conclusion that the rates of first exacerbations, and ratio between those rates changes over time is correct. However, this is entirely in line with statistical theory for repeated events with overall constant rates. It cannot be used to support any conclusion that the difference in the rate of exacerbation is due to a "first month's surge". The "digitised" curve of first events behaves entirely consistently with constant rate events. Drawing any conclusions about the durability of the treatment effect on all exacerbations from this digitised plot, which shows only first exacerbations, is methodologically incorrect.

Consider a repeating event end-point (such as exacerbations) in two treatment groups, A (low constant rate) and B (high constant rate). Initially the gradient of the survival curve for the first event for treatment B (high rate) will be very steep, because all patients are "at risk" of an event. As fewer and fewer patients are left available to have a first event, the gradient will necessarily diminish. The gradient of the survival curve for the first event for treatment A (low rate) will eventually become steeper. Eventually the two survival curves for time to first event will converge despite event rates being different in both arms, as illustrated in the figure, which is described by the equations below.

Suppose that in treatment arm A events occur at a constant annual rate of 1.0 , and in treatment arm B events occur with a constant annual rate of 1.5. The exponential survival functions (i.e. the functions that describe survival for events with constant hazard rates) are given by:

$$
\begin{gathered}
S^{\text {Treatment } A}(t)=1-\exp (-\mathrm{t}) \\
S^{\text {Treatment } B}(t)=1-\exp (-1.5 \mathrm{t})
\end{gathered}
$$

where $t$ is the time in years [3]. The resulting survival curves can be plotted and it is also possible to differentiate with respect to $t$, to obtain the gradient $G(t)=\mathrm{S}^{\prime}(\mathrm{t})$ of the survival curves, which corresponds

@ERSpublications

Evaluation of treatment effect durability over time cannot be based on analyses that examine the first of many events. Here, it is explained how misinterpretation of survival curves led to wrong conclusions in a recent $E R J$ editorial. http://bit.ly/2K3amgQ

Cite this article as: Hartley B, Criner GJ, Dransfield MT, et al. Misinterpretation of time-to-first event curves can lead to inappropriate treatment. Eur Respir J 2019; 54: 1900634 [https://doi.org/10.1183/ 13993003.00634-2019]. 

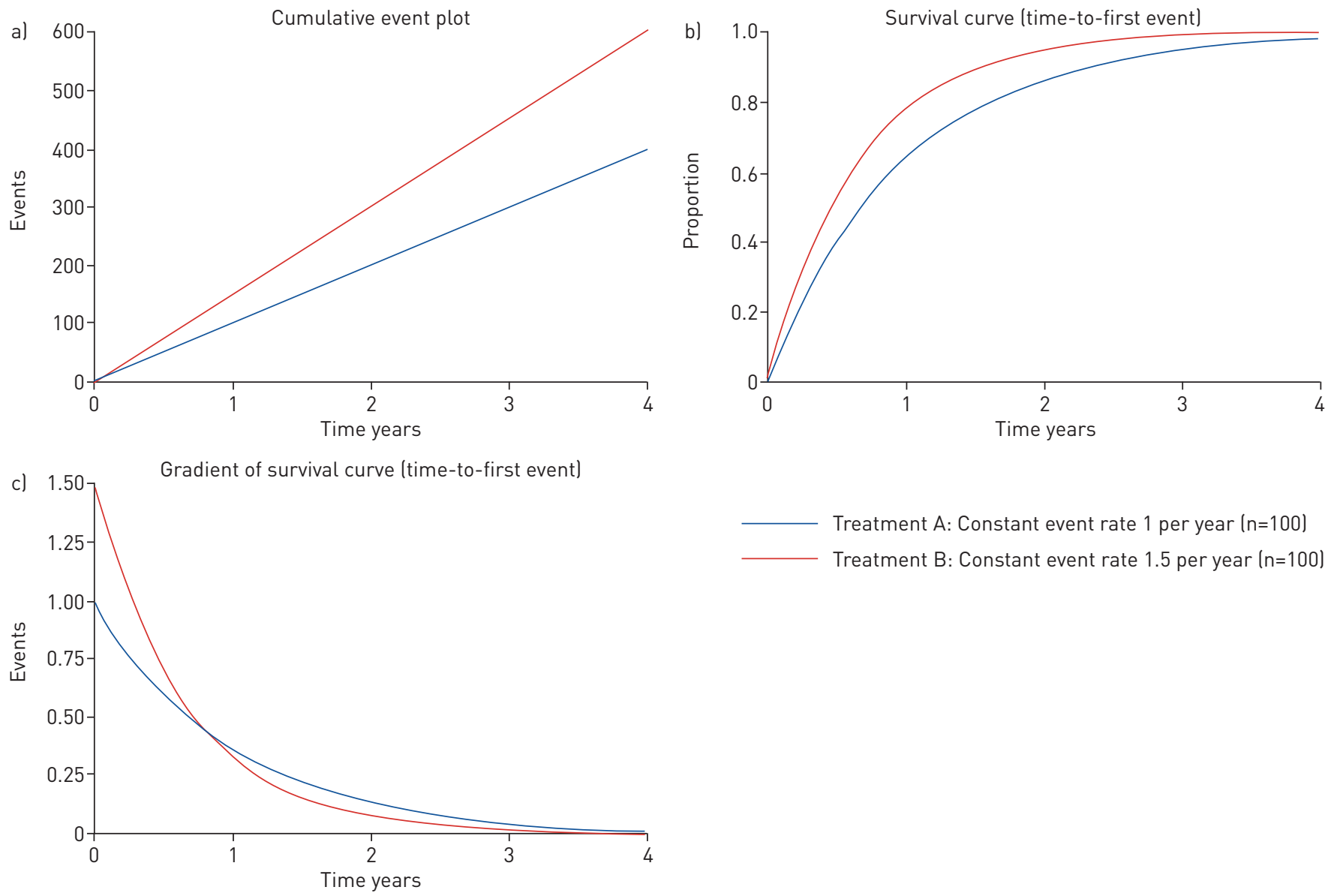

Treatment A: Constant event rate 1 per year $(n=100)$ Treatment B: Constant event rate 1.5 per year $(n=100)$

FIGURE 1 Hypothetical example of a cumulative event plot, survival curve and gradient of survival curve presented on the same data.

to the digitised plot presented by SuISSA and ArIEL [1].

$$
\begin{gathered}
G^{\text {Treatment } A}(t)=\exp (-\mathrm{t}) \\
G^{\text {Treatment } B}(t)=1.5 \exp (-1.5 \mathrm{t})
\end{gathered}
$$

These survival curves converge, and the gradient of both curves start to diminish, with the gradient functions crossing exactly as shown in the real data (figure 1). It is important to understand this phenomenon occurs for constant rate events, and therefore its presence should not be taken as evidence that the rates are not constant.

This can be understood in the following way: the cumulative incidence or survival curve only describes the first event experienced by each patient. If treatment A consistently reduces the rate of events, then these first events will be delayed but they will still occur. While patients on treatment A are experiencing their first events there are simply fewer patients on the treatment B arm who are still "at risk" of a first event, these events having already occurred. By this point patients on treatment B are having second or third events, which are not captured by a time to first event analysis, thus the rate of their first events has diminished.

This illustrates that conclusions about the durability of the treatment effect over time cannot be based on analyses restricted to looking at only the first event of many. To imply that the treatment effect diminishes because one survival curve catches up with another is inappropriate and risks propagating incorrect information, which could lead to harm to patients if treatment is withdrawn or not used.

Benjamin Hartley ${ }^{1}$, Gerard J. Criner ${ }^{2}$, Mark T. Dransfield ${ }^{3}$, David M.G. Halpin ${ }^{4}$, MeiLan K. Han ${ }^{5}$, C. Elaine Jones ${ }^{6}$, Sally Kilbride ${ }^{7}$, Peter Lange ${ }^{8,9}$, David A. Lipson $\oplus^{10,11}$, David A. Lomas ${ }^{12}$, Neil Martin ${ }^{13,14}$, Fernando J. Martinez ${ }^{15}$, Dave Singh ${ }^{16}$, Robert A. Wise $\overbrace{}^{17}$ and Sally Lettis ${ }^{7}$ 
${ }^{1}$ Statistics and Programming, Veramed Ltd, Twickenham, UK. ${ }^{2}$ Lewis Katz School of Medicine at Temple University, Philadelphia, PA, USA. ${ }^{3}$ Division of Pulmonary, Allergy, and Critical Care Medicine, Lung Health Center, University of Alabama at Birmingham, Birmingham, AL, USA. ${ }^{4}$ Dept of Respiratory Medicine, Royal Devon and Exeter Hospital, Exeter, UK. ${ }^{5}$ University of Michigan, Pulmonary and Critical Care, Ann Arbor, MI, USA. ${ }^{6}$ GlaxoSmithKline, Research Triangle Park, NC, USA. ${ }^{7}$ GlaxoSmithKline, Stockley Park West, Uxbridge, UK. ${ }^{8}$ Dept of Public Health, Section of Epidemiology, University of Copenhagen, Copenhagen, Denmark. ${ }^{9}$ Medical Dept, Herlev and Gentofte Hospital, Herlev, Denmark. ${ }^{10}$ GlaxoSmithKline, Collegeville, PA, USA. ${ }^{11}$ Perelman School of Medicine, University of Pennsylvania, Philadelphia, PA, USA. ${ }^{12}$ UCL Respiratory, University College London, London, UK. ${ }^{13}$ GlaxoSmithKline, Brentford, UK. ${ }^{14}$ University of Leicester, Leicester, UK. ${ }^{15} \mathrm{New}$ York-Presbyterian Weill Cornell Medical Center, New York, NY, USA. ${ }^{16}$ University of Manchester, Manchester, UK. ${ }^{17}$ Division of Pulmonary and Critical Care Medicine, Johns Hopkins University School of Medicine, Baltimore, MD, USA.

Correspondence: Sally Lettis, GlaxoSmithKline, Stockley Park West, Uxbridge, Middlesex, UB11 1BT, UK. E-mail: sally.x.lettis@gsk.com

Received: 29 March 2019 | Accepted after revision: 30 May 2019

Conflict of interest: B. Hartley reports grant support and medical writing support funded by GlaxoSmithKline, during the conduct of the study; B. Hartley is a contingent worker on assignment at GlaxoSmithKline, and holds shares in GlaxoSmithKline, outside the submitted work. G.J. Criner reports grant support and medical writing support funded by GlaxoSmithKline, during the conduct of the study; personal fees from Almirall, AstraZeneca, Boehringer Ingelheim, Chiesi, CSA Medical, Eolo, GlaxoSmithKline, HGE Technologies, Novartis, Nuvaira, Olympus, Pulmonx, Verona and NGM Bio, outside the submitted work. M.T. Dransfield reports grant support and medical writing support funded by GlaxoSmithKline, during the conduct of the study; grants from Department of Defense and NIH, has received personal fees for consultancy from and undertaken clinical trials for Boehringer Ingelheim, AstraZeneca, PneumRx/BTG, Boston Scientific and GlaxoSmithKline, undertaken clinical trials for Novartis, Yungjin and Pulmonx, personal fees for consultancy from Genentech and Quark Pharmaceuticals, outside the submitted work. D.M.G. Halpin reports grant support and medical writing support funded by GlaxoSmithKline, during the conduct of the study; personal fees from AstraZeneca, Chiesi, GlaxoSmithKline and Pfizer, personal fees and non-financial support from Boehringer Ingelheim and Novartis, outside the submitted work. M.K. Han reports grant support and medical writing support funded by GlaxoSmithKline, during the conduct of the study; personal fees from AstraZeneca and Boehringer Ingelheim, grant support from Novartis and Sunovion, outside the submitted work. C.E. Jones reports grant support and medical writing support funded by GlaxoSmithKline, during the conduct of the study; C.E. Jones is an employee of and holds shares/ options in GlaxoSmithKline, outside the submitted work. S. Kilbride reports grant support and medical writing support funded by GlaxoSmithKline, during the conduct of the study; S. Kilbride is an employee of and holds shares/options in GlaxoSmithKline, outside the submitted work. P. Lange reports grant support and medical writing support funded by GlaxoSmithKline, during the conduct of the study; personal fees from GlaxoSmithKline, AstraZeneca, Boehringer Ingelheim and Chiesi, outside the submitted work. D.A. Lipson reports grant support and medical writing support funded by GlaxoSmithKline, during the conduct of the study; D.A. Lipson is an employee of and holds shares/options in GlaxoSmithKline, outside the submitted work. D.A. Lomas reports grant support and medical writing support funded by GlaxoSmithKline, during the conduct of the study; grants, personal fees for consultancy and honoraria from GlaxoSmithKline, personal fees for consultancy from Grifols, outside the submitted work. N. Martin reports grant support and medical writing support funded by GlaxoSmithKline, during the conduct of the study; N. Martin is an employee of and holds shares/options in GlaxoSmithKline, outside the submitted work. F.J. Martinez reports grant support and medical writing support funded by GlaxoSmithKline, during the conduct of the study; personal fees and travel support for educational activities from American College of Chest Physicians, Inova Fairfax Health System, MD Magazine, Miller Communications, National Association for Continuing Education, PeerView Communications, Prime Communications, Puerto Rican Respiratory Society, Potomac, University of Alabama Birmingham, Physicians Education Resource, Canadian Respiratory Network and Dartmouth, personal fees for advisory board work, steering committee work and lectures, and travel support from AstraZeneca, personal fees for advisory board work, data monitoring committee work and lectures, and travel support from Boehringer Ingelheim and Genentech, non-financial support for advisory board work from ProterrixBio, personal fees for educational activities from Columbia University, Integritas, Methodist Hospital Brooklyn, New York University, UpToDate, WebMD/MedScape, Western Connecticut Health Network, PlatformIQ, Rockpointe, Rare Disease Healthcare Communications and France Foundation, personal fees for advisory board work and travel support from ConCert, Sunovion, Theravance and Teva, personal fees for advisory board work and non-financial support for travel, lecturing, steering committee work and data monitoring committee work from GlaxoSmithKline, personal fees for advisory board work and lectures, and travel support from Novartis, personal fees for advisory board work and non-financial support for steering committee work from Pearl Pharmaceuticals, personal fees for advisory board work and educational activites, and travel support from Chiesi, non-financial support for steering committee work from Afferent/Merck, Gilead, Nitto, Veracyte, Prometic, Bayer and ProMedior, personal fees for consultancy and steering committee work from Patara/Respivant, non-financial support for data monitoring committee and steering committee work from Biogen, non-financial support for lecturing and advisory board work from Zambon, personal fees for journal editorship from American Thoracic Society, grants from NIH, non-financial support for consultancy from Bridge Biotherapeutics, outside the submitted work. D. Singh reports grant support and medical writing support funded by GlaxoSmithKline, during the conduct of the study; personal fees from GlaxoSmithKline, Cipla, Genentech and Peptinnovate, grants and personal fees from AstraZeneca, Boehringer Ingleheim, Chiesi, Glenmark, Menarini, Mundipharma, Novartis, Pfizer, Pulmatrix, Therevance and Verona, outside the submitted work. R.A. Wise reports grant support and medical writing support funded by GlaxoSmithKline, personal fees for data monitoring committee and advisory board work from GlaxoSmithKline, during the conduct of the study; grants and personal fees for data monitoring committee and consultancy work from AstraZeneca/Medimmune and GSK, grants and personal fees for data monitoring and steering committee work from Boehringer Ingelheim, personal fees for clinical end-point committee work from Contrafect, personal fees for data monitoring committee work from Pulmonx, Roche, Merck and AbbVie, personal fees for steering committee work from Spiration, personal fees for workshops and consultancy from Sunovion, grants from Pearl Therapeutics and Sanofi-Aventis, personal fees for 
consultancy from Circassia, Pneuma, Verona, Denali, Aradigm, Mylan/Theravance and Propelloer Health, personal fees for safety review committee work from Bonti, outside the submitted work. S. Lettis reports grant support and medical writing support funded by GlaxoSmithKline, during the conduct of the study; S. Lettis is an employee of and holds shares/options in GlaxoSmithKline, outside the submitted work.

Support statement: Editorial support (in the form of assembling figures, collating author comments, grammatical editing and referencing) was provided by Chrystelle Rasamison, at Fishawack Indicia Ltd, UK, and was funded by GSK. This study was funded by GSK (study number CTT116855). The funders of the study had a role in the study design, data analysis, data interpretation, and writing of the report. Funding information for this article has been deposited with the Crossref Funder Registry.

\section{References}

1 Suissa S, Ariel A. Triple therapy trials in COPD: a precision medicine opportunity. Eur Respir J 2018; 52: 1801848.

2 Lipson DA, Barnhart F, Brealey N, et al. Once-daily single-inhaler triple versus dual therapy in patients with COPD. N Engl J Med 2018; 378: 1671-1680.

3 Collett D. Modelling Survival Data in Medical Research. 1st Edn. London, Chapman and Hall, 1994; Chapter 1.

Copyright (c)ERS 2019

\section{From the authors:}

We thank B. Hartley and co-workers for their correspondence on our analysis of the IMPACT triple therapy trial [1]. We welcome this opportunity to correct some misunderstanding of the computation of monthly rates of exacerbation, when converted from the cumulative incidence curve, as applied to the IMPACT trial.

The rate of a first exacerbation for a given month of follow-up is based not only on the gradient of the survival function as the numerator, as understood by B. Hartley and co-workers, but must also include the survival function as the denominator denoting the subjects at risk of an exacerbation [2]. Thus, the monthly rate is approximated by the difference between the cumulative incidence value at the end of each month with that at the beginning of that month, divided by the survival at the beginning of the month. Using the notation of B. Hartley and co-workers (somewhat confusing since $\mathrm{S}(\mathrm{t})$ is typically used to denote the survival function, not the cumulative incidence function as employed in their correspondence), the "rate" at a given point in time (hazard function) is:

$$
h(t)=G(t) /(1-S(t)) .
$$

The corresponding average rate over a given time interval $t_{1}$ to $t_{2}$ is given by:

$$
\text { rate }=\left(S\left(t_{2}\right)-S\left(t_{1}\right)\right) /\left(\left(t_{2}-t_{1}\right)\left(1-S\left(t_{1}\right)\right)\right)
$$

This is the monthly rate of exacerbation displayed in our figure for the long-acting muscarinic antagonist (LAMA)-long-acting $\beta$-agonist (LABA) and triple therapy groups, approximated from the cumulative incidence curves, for the IMPACT trial [1]. It clearly shows that the first month's surge in the rate of exacerbation in the LAMA-LABA group is real, with no differences in the subsequent rates between the two groups during the following 11 months. Thus, contrary to the claim of B. Hartley and co-workers, this proper calculation of the rate supports the conclusion that the difference in the rate of exacerbation between the two groups is due to the first month's surge.

This pattern of an early surge, known as "depletion of susceptibles", can be informative to understand a treatment's effect [3]. This sudden surge is not unexpected in the IMPACT trial with the abrupt withdrawal of inhaled corticosteroids (ICS) imposed at randomisation and its inclusion of a patient

@ERSpublications

The IMPACT trial of triple therapy in COPD confirms that benefit on exacerbations is only in first month with no benefit in following 11 months, likely due to inclusion of asthma-like patients, suggesting a precision medicine opportunity in COPD treatment http://bit.ly/2YxQpH0

Cite this article as: Suissa S, Ariel A. Misinterpretation of time-to-first event curves can lead to inappropriate treatment. Eur Respir J 2019; 54: 1901275 [https://doi.org/10.1183/13993003.01275-2019]. 
population with a history of asthma, over-represented by frequent exacerbators with milder airflow limitation [4].

Rather than this mathematical sophistication, it would have been more straightforward and certainly more informative if B. Hartley and the authors of the IMPACT trial had simply provided estimates for these monthly rates of an exacerbation directly from the trial data available to them. The authors could then confirm the surge with the actual trial data, and also investigate the role of prior ICS use that was abruptly discontinued at randomisation, as well as prior asthma diagnosis, frequent exacerbator phenotype, GOLD stage and eosinophilia, on this surge. Such analyses would provide valuable data for a better precision medicine targeting of the right treatment for the right patient [5]. Most importantly, this would also allow to prevent unnecessary harms from ICS to those patients who would not benefit from triple therapy.

Samy Suissa ${ }^{1}$ and Amnon Ariel ${ }^{2}$

${ }^{1}$ Center for Clinical Epidemiology, Lady Davis Institute, Jewish General Hospital, and the Depts of Epidemiology and Biostatistics and of Medicine, McGill University, Montreal, QC, Canada. ${ }^{2}$ Lung Unit, Emek Medical Center, Afula, Israel.

Correspondence: Samy Suissa, Centre for Clinical Epidemiology, Jewish General Hospital, 3755 Cote Ste-Catherine, Montreal, QC, Canada H3T 1E2. E-mail: samy.suissa@mcgill.ca

Received: 26 June 2019 | Accepted after revision: 27 June 2019

Conflict of interest: S. Suissa reports personal fees for board membership from Novartis and Boehringer Ingelheim, grants from Boehringer Ingelheim/Pfizer, personal fees for lectures from AstraZeneca, outside the submitted work. A. Ariel reports personal fees from AstraZeneca and Teva, personal fees and non-financial support from Boehringer Ingelheim, outside the submitted work.

\section{References}

Suissa S, Ariel A. Triple therapy trials in COPD: a precision medicine opportunity. Eur Respir J 2018; 52: 1801848 Collett D. Modelling Survival Data in Medical Research. London, Chapman and Hall, 1994.

Renoux C, Dell'Aniello S, Brenner B, et al. Bias from depletion of susceptibles: the example of hormone replacement therapy and the risk of venous thromboembolism. Pharmacoepidemiol Drug Saf 2017; 26: 554-560.

4 Suissa S, Ariel A. Triple therapy in COPD: only for the right patient. Eur Respir J 2019; 53: 1900394.

5 Suissa S, Ernst P. Precision medicine urgency: the case of inhaled corticosteroids in COPD. Chest 2017; 152: $227-231$. 